\title{
FORMAÇÃO CONTINUADA DE PROFESSORES: O QUE MUDA COM A IMPLANTAÇÃO DE 1/3 DA CARGA HORÁRIA DOCENTE SEMANAL PARA ATIVIDADES EXTRACLASSES NO ESPAÇO ESCOLAR?
}

\author{
NATHALIA BEZERRA DA SILVA FERREIRA \\ Mestranda em Letras pela Universidade do Estado do Rio Grande do Norte-UERN. Pós-graduada em Coordenação \\ Pedagógica pela Universidade Federal do Ceará-UFC e em Literatura e Formação de Leitores pela Universidade Esta- \\ dual do Ceará-UECE Graduada em Letras Inglês pela mesma instituição de ensino. Professora de Língua Inglesa da \\ Rede Pública Estadual do Ceará. \\ E-mail: nathalia.bzr@gmail.com
}

\section{RESUMO}

No ano de 2011, a rede pública de ensino médio do Ceará passou a garantir o cumprimento da lei 11.738/2008 que além da instituição de um piso salarial para os professores, garante também que, 1/3 da jornada de trabalho seja utilizado para planejamento e outras atividades fora de sala. A formação continuada é uma das atividades que devem ser realizadas nesse momento. Essa formação é essencial para o docente, que além de se atualizar com as atuais correntes teóricas de sua disciplina, pode também, refletir sobre o seu fazer docente. A prática atual precisa ser refletida constantemente para que o professor possa melhorá-la quando for necessário, com o objetivo de garantir a aprendizagem. Embora a formação continuada seja assunto recorrente dentro dos estudos sobre educação, observa-se a necessidade de um estudo que busque analisar o impacto dessa mudança na formação dos professores das escolas de ensino médio do estado do Ceará, mas precisamente na cidade de Quixadá. Diante dessa situação, o presente trabalho tem por objetivo analisar o aumento de horas extraclasse, principalmente em relação ao impacto que esse acréscimo de carga horária teve na formação docente. Partimos, desse modo, do pressuposto de que a escola é o principal lugar para formação continuada dos docentes. Para tanto, foi realizada uma pesquisa de campo na Escola de Ensino Médio José Martins Rodrigues no município de Quixadá, Ceará, pesquisa essa que busca observar os fatos relacionados a formação de professores para que possamos estabelecer relações entre a prática que ocorre na escola com o que propõem os estudiosos em educação. Nesse sentido, observou-se que o cumprimento da lei tem favorecido as práticas de formação em exercício dos profissionais do magistério. Trata-se de um estudo de caso, que se divide quanto a sua abordagem em qualitativa e quantitativa.

Palavras-Chave: Formação continuada. Atividade extraclasse. Prática docente

\section{TEACHERS' CONTINUING TRAINING: WHAT HAS CHANGED SINCE THE IMPLEMENTATION OF 1/3 OF THE WEEKLY SCHOOL SYLLABUS TO EXTRA-CLASS ACTIVITIES AT SCHOOL?}

\begin{abstract}
In 2011, the public school system of Ceará started to enforce the law 11.738 / 2008 in addition to the establishment of a minimum wage for teachers, also ensures that $1 / 3$ of the working day to be used for planning and other activities outside the classroom. Continuing education is one of the activities that must be performed at that time. Such activity is essential for the teacher, who needs to catch up with theoretical currents of his discipline, he can also reflect of his teaching. The current practice needs to be reflected constantly so teacher can improve it when necessary, in order to ensure learning. Although continuing education is recurring theme within the studies on education, there is the need for a study that aims to analyze the impact of this change in the high schools teacher's continuing education in the state of Ceará, but precisely in Quixadá city. Given this situation, this paper aims to examine the increase in extra-time, especially the impact on teacher's continuous education. For this purpose, a field research in High School José Martins Rodrigues in Quixadá City was held, research that aims to observe the facts related to teacher training so that we can establish relationships between their practices that takes place at school with the proposing scholars in education. In this sense, we conclude that law enforcement has it favored the practice of teacher's continuous education. It is a case study that was divided in its approaches in qualitative and quantitative.
\end{abstract}

Key-Words: Out-Of-Class Activities Continuing Education. . Teaching Practice 


\section{Introdução}

A formação de professores constitui-se assunto recorrente dentro do campo da educação. Autores como Paulo Freire, Antonio Nóvoa, Selma Garrido Pimenta, entre outros, dedicam uma atenção especial às pesquisas sobre a formação de professores. Na América Latina, essa preocupação é de certa forma recente, pois tomou forma a partir da década de 90 (RODRIGUEZ, 2008, p.37). Embora antes disso já houvesse intenções de se debater sobre a formação de professores, foi apenas nesse período que ganhou proporções maiores. Já é sabido da necessidade constante da formação deste profissional que atua nas bases de todos os demais profissionais.

Para realizar seu trabalho com mais qualidade o professor, além de sua formação inicial, precisa também, atualizar-se constantemente. É nesse contexto que surge a necessidade de uma formação continuada. A formação inicial, por melhor que seja não exclui a necessidade de uma formação no exercício do trabalho docente. Esta é um processo permanente ligada aos saberes docente. Se na universidade o aluno do curso de licenciatura tem a oportunidade de adquirir o embasamento teórico para o exercício da prática docente, é no dia a dia da profissão que se aprende a prática (PIMENTA, 2005, p.72).

Quando se vê diante da realidade e do dinamismo do contexto escolar, o recém-professor precisa agora refletir, buscar teorias que possam embasar suas ações e melhorar seu trabalho fundamentado em sua prática. A teoria sem a prática não aponta os caminhos necessários que nos levam à aprendizagem. Por sua vez, não há um caminho sem uma teoria, sem o saber docente, esses dois elementos devem ser indissociáveis. Freire (1987, p. 94) é categórico ao afirmar que a teoria sem a prática é verbalismo e prática sem teoria é ativismo. Para ele, é necessário que estejam juntas formando assim a práxis, sendo esta sim transformadora de realidades.

Diante da importância da formação docente, há uma vasta produção acadêmica sobre a formação continuada dos profissionais da educação. Entretanto, diante do recente aumento de horas para que os professores possam planejar, garantido pela lei $n^{\circ} 11.738$ de 2008 (art. $2^{\circ}$ ) que, entre outras coisas, estabelece que no mínimo $1 / 3$ de sua carga horária seja utilizada em atividades extraclasse, observa-se a necessidade de um estudo que busque analisar o impacto dessa mudança na formação dos docentes das escolas de ensino médio do estado do Ceará, mais precisamente na cidade de Quixadá.

Nesta pesquisa, busca-se analisar a formação docente a partir da identificação dos desafios pertinentes a formação continuada, como o tempo para realização destas atividades, o interesse dos professores, e mais especificamente, o aproveitamento destas horas dentro da unidade escolar, considerando o 1/3 dedicado ao planejamento. Para tanto, elegemos como objeto de estudo a Escola 
Estadual José Martins Rodrigues, situada no Sítio Nova Aurora, s/nº, Cedro, que desde 2012 trabalha como essa nova carga horária. Esta escola foi escolhida porque atuo nela como coordenadora escolar. Tomá-la como meu objeto de estudo parte de minha preocupação do andamento da formação continuada da escola e, principalmente, de analisar, perceber o que pensam os professores sobre essa necessidade de se manter em contínua formação.

A formação continuada fazendo parte do planejamento escolar é um caminho para a reflexão sobre a prática, que só pode ser transformada através da reflexão sobre ela. É refletindo que encontramos respostas; que nos direcionamos à caminhos menos tortuosos na educação brasileira. Refletimos, identificamos problemas, para então, agirmos sobre ele.

Em seu texto Pedagogia da Autonomia, Paulo Freire reflete sobre a prática docente: "não há docência sem discência, as duas se explicam, e seus sujeitos, apesar das diferenças que os conotam, não se reduzem a condição de objeto um do outro. Quem ensina aprende ao ensinar, e quem aprende ensina ao aprender" (FREIRE, 2014, p. 23). Assim, percebemos que a prática docente só é possível por meio dela mesma, que só nos tornamos professores quando reconhecemos nos alunos a capacidade de também nos ensinar. Nesse processo de ponte entre teoria e prática, entre discentes e docentes, temos no diálogo uma peça fundamental.

Buscando compreender a formação de professores em exercício, alguns questionamentos nos vêm à tona: Como é a formação docente nas escolas? Quais são os principais desafios que esses professores enfrentam em relação ao investimento em suas formações? O que o aumento de horasatividade contribui para que haja concepção no espaço escolar? São esses questionamentos que nos inquietam e nos fazem ir para o seio da escola, que é o locus da formação de professores, no intuito de encontrar as respostas necessárias.

Aos quatorze anos, conheci na oitava série do ensino fundamental na cidade de Mauá-SP, uma professora de história que apesar de não relembrar seu nome, marcou uma fase de minha vida e teve um impacto sobre o que hoje sou como educadora. Mesmo sendo professora de história, reativou a biblioteca da escola e mostrou a turma que independente de onde estamos ou o que fazemos, podemos sim ter uma ação sobre o que acontece ao nosso redor no sentido de tentarmos melhorá-lo.

Através dessa professora, tornei-me voluntária da biblioteca da escola. Apesar de ter assumido o compromisso apenas duas vezes na semana, todos os dias passava minhas manhãs naquele local. Nessas manhãs descobri todas as possibilidades que um livro pode oferecer a uma jovem menina. Lia compulsivamente de poesia a biografias, o que encontrava pela frente começava 
a ler.

Não recordo em que momento, mas sei que inspirada pelo exemplo, decidi que seria professora também, apesar de não saber em que área queria atuar. Tudo o que queria era ser professora, a escolha da disciplina veio depois.

Após um ensino médio divido entre o estado de São Paulo e o Ceará, no ano de 2006 prestei vestibular na Faculdade de Educação, Ciências e Letras do Sertão Central para o curso de LetrasInglês. Aprovada, iniciei minha vida acadêmica e pude comprovar que tinha feito a escolha certa. Era como estudante de um curso de licenciatura que me realizava na expectativa de poder iniciar a minha vida docente.

No ano de 2009, fiz uma seleção na 12a CREDE (Coordenadoria Regional de Desenvolvimento da Educação) e fui selecionada para assumir as turmas de $1^{\circ}$ e $2^{\circ}$ anos de ensino médio. Foi um momento difícil de transição de gestores na escola, assumi a sala de aula pela primeira vez e não tive nenhuma orientação pedagógica. Mesmo com toda essa dificuldade inicial, percebi que minha vontade de ser professora não diminuía, na verdade, hoje percebo que só foi aumentando. Neste mesmo ano, fiz o concurso da rede estadual e também da prefeitura de Quixadá. Fui aprovada nos dois, mas como ainda não havia terminado a graduação, só pude tomar posse como efetiva da rede estadual quando conclui o curso de licenciatura em 2011.

Durante esse percurso, decidi diminuir o ritmo como professora e me dedicar mais ao curso de letras. Nesse período, fui bolsista de iniciação a docência do Núcleo de Línguas por dois anos. Atuei também como professora da educação infantil, do ensino fundamental e de jovens e adultos.

Tomei posse como efetiva em uma escola da cidade de Ibaretama-CE, escola esta, em que me realizava como professora, apesar das muitas dificuldades, como o nível de aprendizagem, sempre fui muito bem orientada pela coordenadora escolar. Esta, sempre analisava em que precisávamos melhorar e nos ajudava a traçar estratégias para alcançarmos uma aprendizagem efetiva. Atuei como professora nessa instituição até a metade do ano de 2013, quando fiz uma seleção para os gestores estaduais e fui convidada a ocupar a função de Coordenadora Escolar na escola José Martins Rodrigues

Assumi a coordenação com muito receio, porém mais uma vez, tirei como base o bom exemplo de coordenadora que pude ter na escola anterior para fundamentar a minha prática. Até os dias atuais, continuo como coordenadora. Assumindo esta função, hoje, como formadora docente no espaço escolar, tendo em vista que, dentro da atuação de um coordenador pedagógico, uma das 
principais funções é promover a formação continuada dos profissionais da escola, me sinto instigada sobre o aproveitamento da hora-atividade nas escolas da rede estadual.

Tomamos por local base para a formação continuada dos docentes o espaço escolar, pois é este o ambiente em que o professor ao pôr em prática os saberes adquiridos na sua formação inicial, depara-se com a realidade. Quando deparado com a realidade, começam então a surgir as primeiras dúvidas e os anseios pertinentes a profissão.

Além de ser o local em que se dá aprendizagem, valorizamos o espaço escolar para a formação docente por acreditar que nesse espaço os professores encontram seus companheiros de trabalho que, muitas vezes, passam ou passaram por situações semelhantes de angústia. Nesse contexto, o professor pode compartilhar a teoria, discutir e analisar a prática com seus pares, a fim de buscar um posicionamento.

Planejar é uma ação pertinente ao ser humano. Quando planejamos, refletimos os objetivos que temos e traçamos estratégias para alcançá-los. Após lançarmos as metas, precisamos verificar se foram alcançadas. Esse momento se dá através do diálogo entre os docentes, no chamado planejamento por área do conhecimento nas escolas de ensino médio. Nesse contexto, semanalmente, os professores se reúnem por áreas afins (Ciências Humanas, Ciências da Natureza e Linguagens e Códigos) para que possam participar de formações, organizarem seu material de trabalho, planejarem suas aulas, entre tantas outras atividades.

\section{Procedimentos Metodológicos}

O presente trabalho trata da formação dos professores da Escola Estadual de Ensino Médio José Martins Rodrigues e se caracteriza por ser uma pesquisa de campo em que se busca observar os fatos relacionados a formação de professores para que possamos estabelecer relações entre a prática que ocorre na escola com o que propõem os estudiosos em educação. Trata-se, pois, de um estudo de caso, que se divide quanto a sua abordagem em qualitativa e quantitativa. Essa divisão se dá pelo teor que o questionário aplicado possui.

A aplicação do questionário foi realizada em novembro de 2014, feita através de troca de emails, para que os professores se sentissem confortáveis para responder as perguntas e, principalmente, para que respondessem no momento que lhes fossem mais oportuno, sem interferir na rotina. O questionário foi aplicado com o intuito de levantar dados a respeito de como era a formação inicial antes da ampliação da carga horária para as horas-atividade e como está agora, buscando compreender a realidade escolar e os mecanismos de planejamento dessa escola pública 
do estado do Ceará.

Após as coletas de dados, partimos para a análise do material. Nesse momento, buscamos estabelecer um perfil desses profissionais, criando relações com o objetivo maior desta pesquisa que é o de conhecer como se dá na prática a formação de professores no dia a dia da escola. Os resultados obtidos em cada resposta do questionário são apresentados em forma de gráfico e analisados individualmente.

\title{
Formação de Professores
}

Formar professores pressupõe aceitar o inacabamento humano. Mas vai além, uma vez que a profissão exige ainda mais do ser em questão. Essa formação não existe um momento em que não se faça mais necessária, como afirma Barreto:

\begin{abstract}
“A formação docente não tem um ponto exato que caracteriza sua conclusão. Por essa razão, pode-se afirmar que essa formação, em especial, tem um caráter permanente e se fecunda na prática, no local de trabalho, na escola. Nesse sentido, a escola não assume apenas um caráter de ensino, mas essencialmente de aprendizagem, não apenas para o aluno, mas em especial para o professor, o que implica considerar a escola como o lugar mais apropriado para se promover a reflexão teórica e prática a cerca do trabalho docente." (BARRETO, 2011, p. 227.)
\end{abstract}

Nesse contexto, a escola surge como o local essencial da formação de professores. Assim, vemos a escola como o local em que o professor além de ensinar pode e deve aprender. Esse aprendizado pode ser com seus alunos, mas aqui, nos focamos na formação com seus pares.

Sobre a utilização do espaço escolar para a formação de professores, Barreto ainda acrescenta:

(...) Enquanto a formação inicial deve propiciar uma relação mais estreita com o contexto de trabalho, favorecendo pensar as disciplinas a partir das necessidades da prática, a formação continuada precisa ser pensada e concretizada na própria escola, com base nos saberes e experiências dos professores, forjada na situação de trabalho. Isso pressupõe uma ideia de formação que estabelece estreita relação entre as práticas formativas e o contexto de trabalho. Institui-se uma concepção de formação centrada na ideia de escola como unidade básica da mudança educativa. (BARRETO, 2011, p. 237)

Aqui, Barreto (2011) chama atenção para a necessidade de uma formação de professores que esteja voltada para ações práticas, ações que sejam pensadas e realizadas dentro do espaço escolar. Nessa perspectiva, temos a ideia de que nada melhor do que as pessoas que estão diretamente envolvidas no processo de ensino aprendizagem possam refletir e buscar as soluções.

Antonio Nóvoa, também defende a ideia de uma formação de professores reflexiva: “A formação continuada deve alicerçar-se numa reflexão na prática e sobre a prática”, através de dinâmicas de investigação-ação e de investigação-formação, valorizando os saberes de que os 
professores são portadores. (NÓVOA, 1991, p.30).

Entretanto,não podemos pensar que simplesmente pelo fato de se promover a formação continuada, teremos resolvido todos os problemas encontrados na área da educação:

A formação continuada como geradora de mudanças insere-se um quadro político prospectivo, em que formação é idealmente participar do futuro(Goguelin,1970) a partir do presente, e assumir o risco para formar é mudar de forma que pode implicar em deformar! Mas que devemos considerar de vital importância é ter sempre presente que educação continuada não é apenas transmissão de conhecimentos científicos, mas, também, de atitudes em relação a esses conhecimentos. (MARIN, 1995, p.27)

Desse modo, devemos lembrar que ao dar forma (formar), podemos estar dando a forma errada. É por isso que afirma que, mais do que transmitir esses conhecimentos, a formação de professores deve se preocupar, principalmente, com a aplicação desses conhecimentos. Além de aprendermos, tomarmos conhecimento de algumas coisas, precisamos por em ação dentro da prática docente de cada dia.

\section{Resultados e Discussão}

Ao pensar a formação continuada centrada na escola, busca-se no presente trabalho, analisar como esses momentos tem acontecido dentro da EEM José Martins Rodrigues. Assim, analisando as respostas dos professores selecionados para responderem ao questionário, podemos ver dentro de um contexto especifico como está sendo aproveitado o tempo extraclasse para o investimento na formação de todos os profissionais da escola.

Quatro professores responderam ao questionário. A escolha desse número para a aplicação de questionário se dá pelo fato de que dentro do atual quadro de professores, que é de 28 (vinte e oito), apenas 08 (oito) se encaixam no perfil estabelecido para a pesquisa de ter pelo menos quatro anos de experiência em sala de aula. É preciso que o professor tenha essa experiência mínima para que ele tenha passado pelo período de ampliação de carga horária para atividade extraclasse. Dentre os professores selecionados, apenas um pertence ao quadro efetivo da escola, os demais são contratados por tempo determinado.

Dos quatro docentes selecionados para responderem ao questionário, temos três professoras e um professor. Eles atuam na educação há pelo menos quatro anos, como dito anteriormente, com idades entre 26 e 52 anos, todos com a formação mínima de graduados. O questionário é composto por dez questões objetivas e uma subjetiva. Nessas questões buscamos montar um perfil desses profissionais e, principalmente identificar os pensamentos deles no que diz respeito a formação continuada. 
Dos professores selecionados temos dois que estão na faixa entre 26 a 30, um de 36 a 40 e um acima de 41 anos. Como podemos evidenciar no gráfico 1, a seguir, a maioria dos professores é jovem.

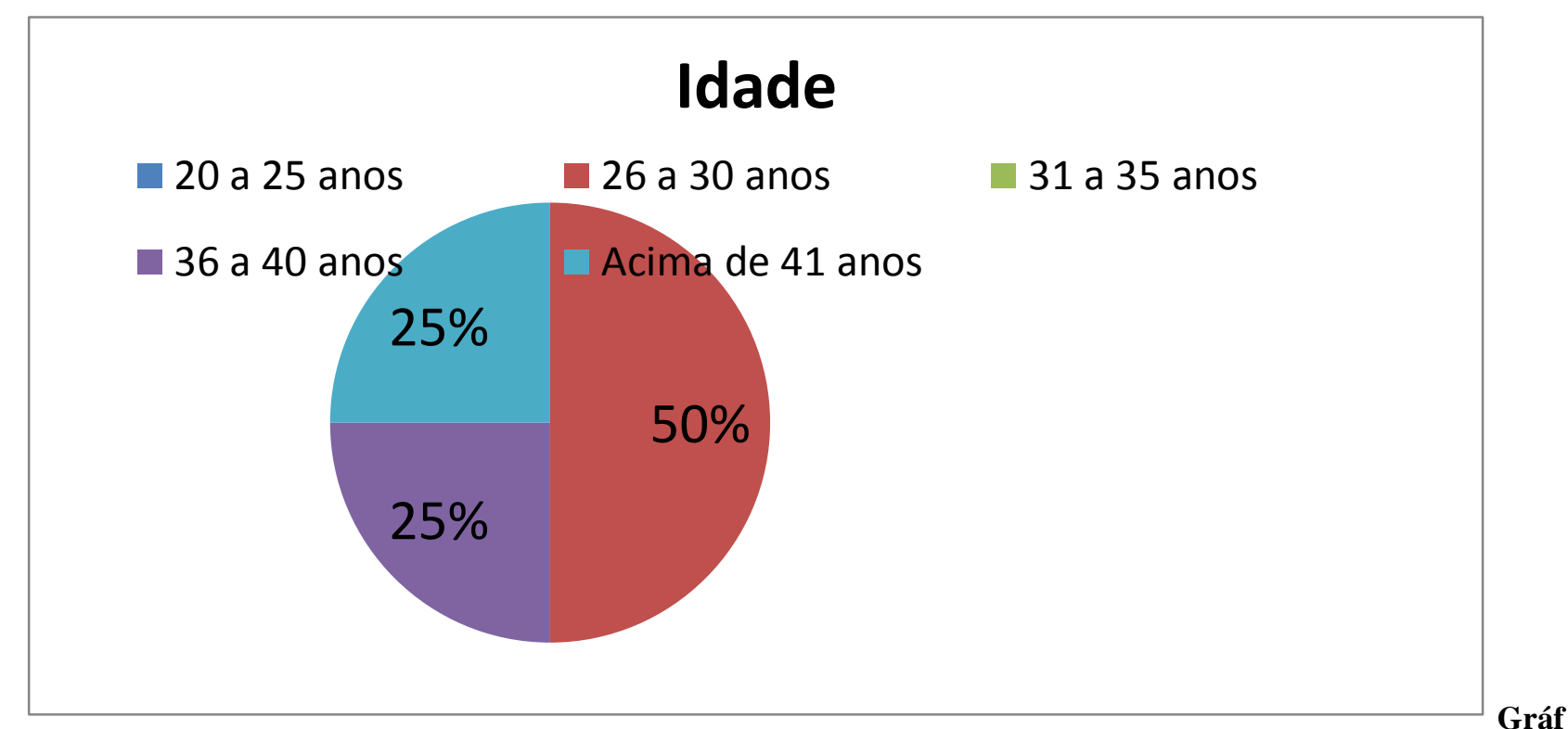

ico 1 - Faixa etária dos professores

Os dados obtidos quanto a idade dos professores selecionados, demonstram um quadro de professores bem jovem consoante com o quadro geral da escola. Esses novos profissionais, em idade e em experiência, chegam, como constatado anteriormente, cheios de dúvidas e anseios e podem, com os desenvolvimento contínuo de formações, conseguir desenvolver todas as suas potencialidades enquanto professores de educação básica.

No gráfico 2 observa-se o tempo de magistério dos professores que fizeram parte da pesquisa:

\section{Tempo de Magistérios}

1 a 3 anos 4 a 6 anos 7 a 9 anos $\square 10$ a 13 anos $\square$ Acima de 14

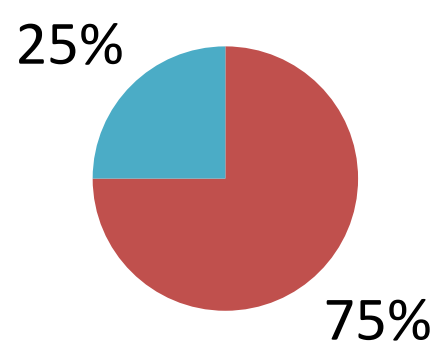




\section{2 - Tempo de magistério dos professores}

O tempo de magistério foi quesito chave para a seleção da amostra, pois é necessário que esses professores tenham acompanhado a mudança do horário extraclasse. Desses profissionais, apenas um possui mais de 14 anos de profissão e os demais possuem de quatro a seis anos. Essas informações, dialogam com o gráfico anterior, pois comprovam que esses professores são ainda muito novos no magistério.

Dos professores pesquisados, um é graduado e três são especialistas (Gráfico 3)

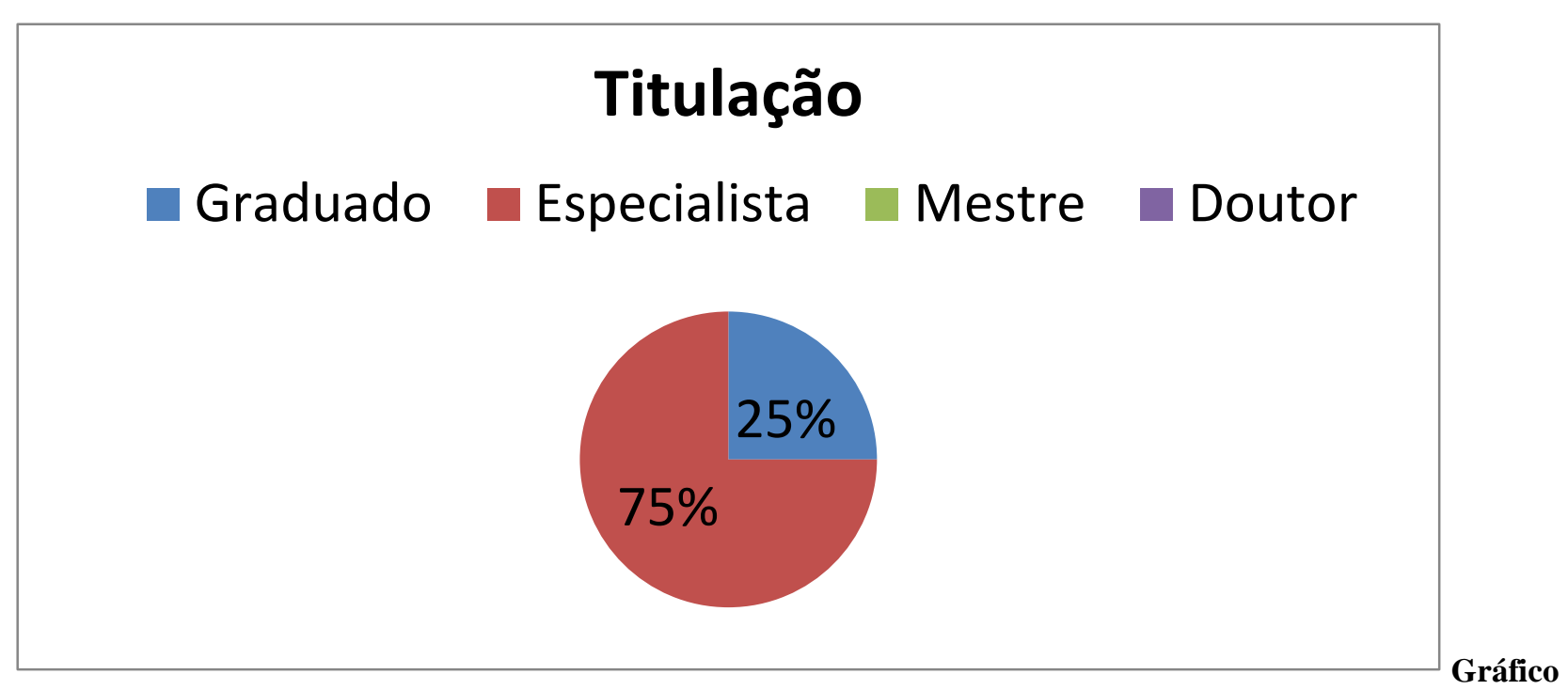

3 - Nível de formação dos professores

Analisando a relação entre os cursos de graduação cursados e as disciplinas que lecionam, todos os professores possuem habilitação na sua área de atuação (Gráfico 4). No caso dessa amostra, de dois são professores de História, um de Matemática e um de Língua Portuguesa.

\section{Habilitação na área}

\section{Sim Não Não, mas possui especialização}

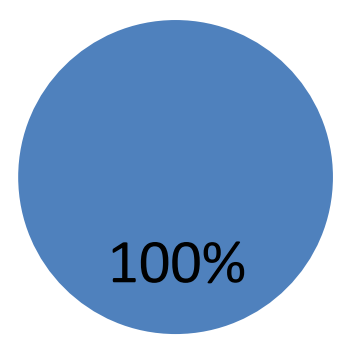


4 - Relação entre os cursos de graduação cursados e as disciplinas que os professores lecionam

No gráfico 5, observam-se as horas semanais de dedicação de cada professor à sua formação. Podemos observar que $75 \%$ dos professores afirmaram dedicar semanalmente de uma carga horária de pelo menos sete horas de estudos. Esse número remete uma postura ativa desses profissionais que estão mais preocupados em manter-se atualizados. Evidencia que estão de acordo com a nova demanda de profissionais que devem ser também pesquisadores, preocupados com o seu autodesenvolvimento:

[...] A nós professores cabe investir nos processos e autoconhecimento e autodesenvolvimento, que implica nos responsabilizarmos pelo projeto do nosso crescimento, tornando-nos sujeitos/agentes transformadores, criadores e diretores do nosso próprio projeto de vida. (PORTAL apud ANTUNES e SANTOS, 2013, p 305)

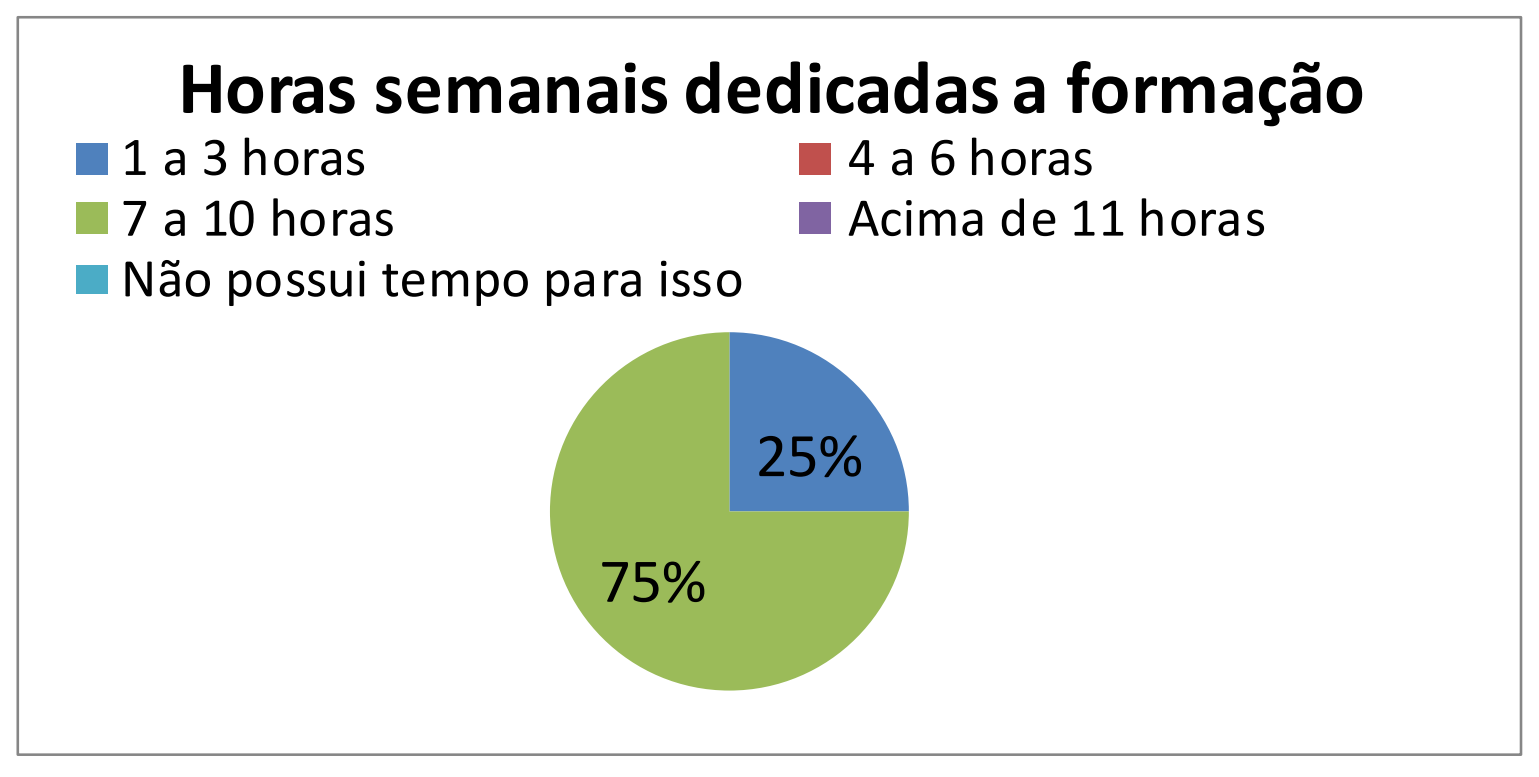

Gráfico

\section{5 - Horas semanais dedicadas à formação}

$\mathrm{Na}$ análise do questionário a seguir, buscamos estreitar as perguntas com o objeto de estudo. Sobre a rotina da escola, ao tentar evidenciar se na escola os professores possuem tempo para a formação continuada, observa-se que $100 \%$ afirma haver tempo disponibilizado pela instituição para a formação continuada. Quando perguntados sobre o funcionamento da escola, sobre a formação continuada, todos os docentes afirmaram que dentro das 13 horas semanais disponibilizadas para as atividades extraclasse a mesma disponibiliza tempo para atividades de formação docente.

Esse resultado demonstra que a escola a escola está ciente de seu papel formador, favorecendo assim, a criação de um ambiente em que o professor possa além de ensinar, aprender. Como sugere Nóvoa: 
"A formação continuada deve estar articulada com desempenho profissional dos professores, tomando as escolas como lugares de referência. Trata-se de um objetivo que só adquire credibilidade se os programas de formação se estruturarem em torno de problemas e de projetos de ação e não em torno de conteúdos acadêmicos". (NÓVOA, 1991, p.30).

No gráfico 6, questionou-se a respeito de como era a disponibilidade de tempo antes de 2012, anterior a ampliação do tempo para planejamento. Nesse caso, a opinião ficou dividida: 50\% afirmou que antes do aumento das horas-atividade, não havia tempo dedicado na escola para a formação continuada, e outros $50 \%$ afirmou que havia tempo disponível, mas somente uma vez por mês.

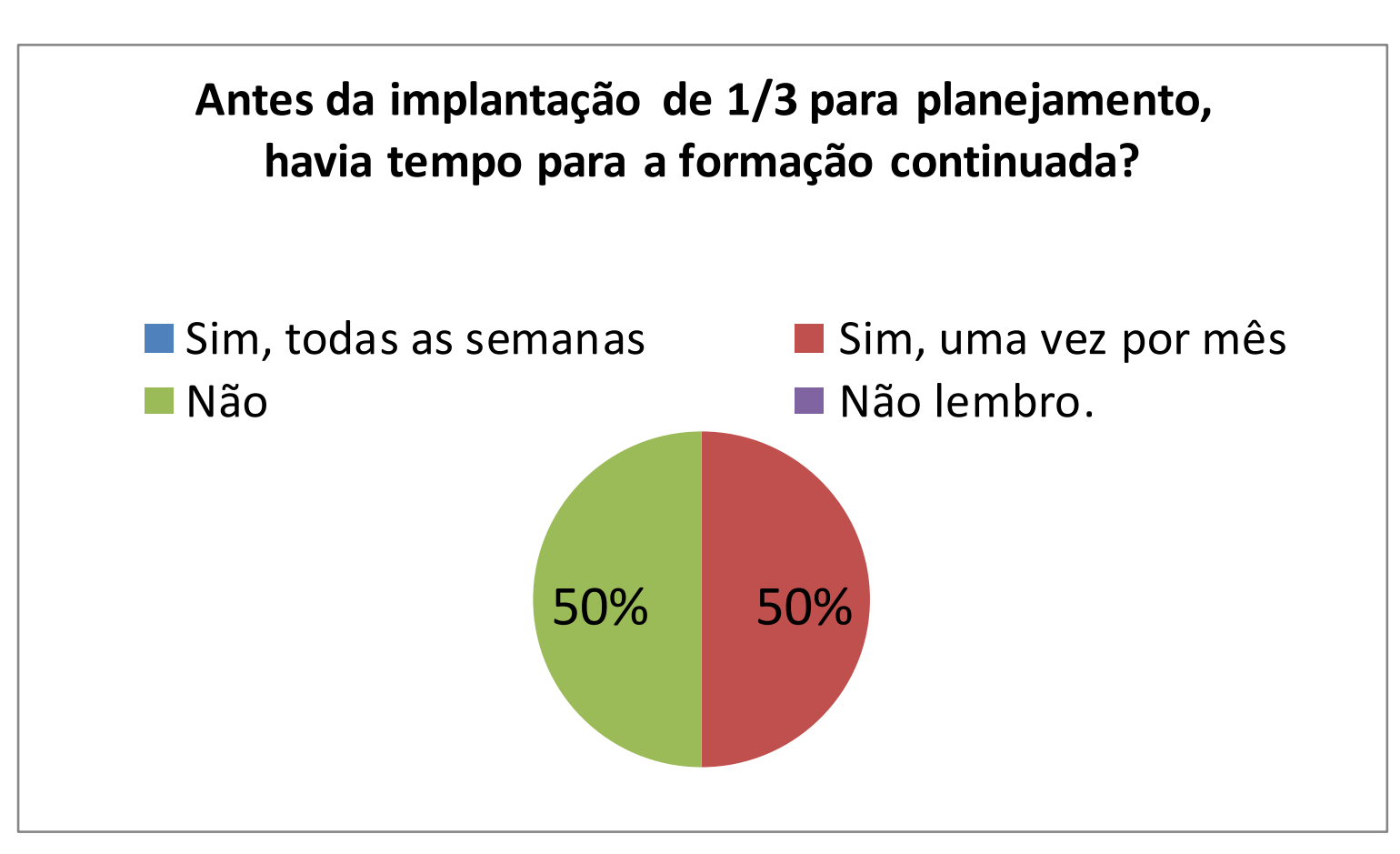

Gráfic o 6 Dispo nibilid ade de tempo para forma ção contin uada antes da impla ntaçã 1/3 para planejamento

Quando questionados se após a implantação dos 1/3 de atividade extraclasse houve ampliação do tempo dedicado à formação continuada, 100\% dos professores afirmam terem percebido que com o advento do 1/3 tiveram acréscimo para os momentos de estudos dentro da escola.

Nóvoa (2000, p. 67) remete para necessidade de troca de experiência no espaço escolar e defende a escola como sendo o local mais apropriado para a formação docente: “(...) é no espaço concreto de cada escola, em torno de problemas pedagógicos ou educativos reais, que se desenvolve a verdadeira formação do professor". Diante da importância de se ter na escola um local de 
aprendizado para o professor, podemos identificar que a conquista do $1 / 3$ têm favorecido essa prática.

No gráfico 7, verifica-se a avaliação dos professores quanto ao tempo disponível pela lei do 1/3. 75\% considerou que consegue realizar suas atividades, que são de: planejamento, correção de atividades, elaboração de provas, etc. Embora precisem correr contra ele para conseguir dar conta de todas essas atividades. Já $25 \%$ considerou que o tempo ainda é pequeno.

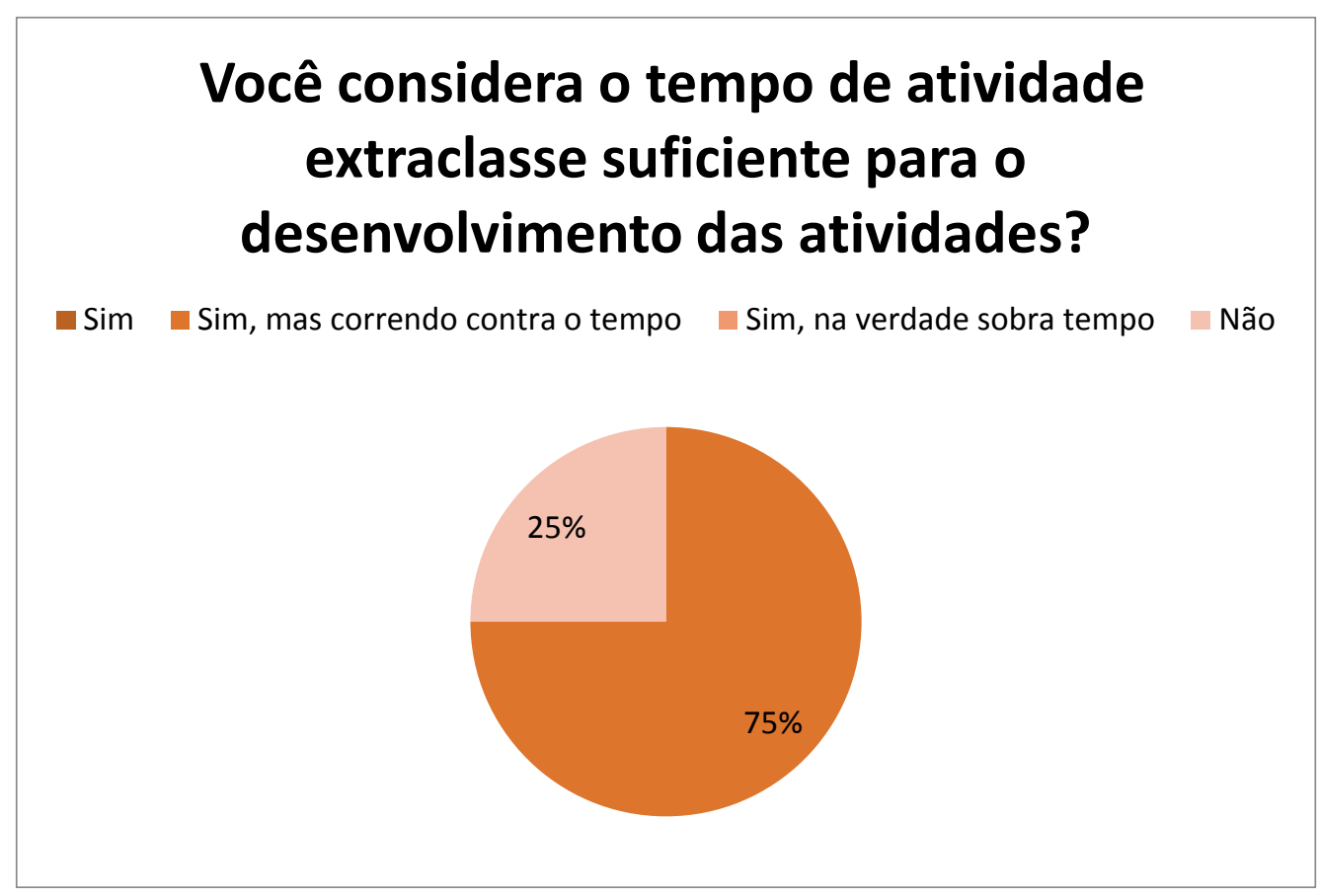

Gráfico 7 - Avaliação dos professores quanto ao tempo de atividade extraclasse

A partir desse resultado, podemos perceber que embora tenha ocorrido um avanço nas horas dedicadas as atividades extraclasse, eles ainda se sentem angustiados, como se estivessem correndo contra o tempo para conseguir dar conta de todas as demandas que a profissão exige.

Finalizando a parte objetiva do questionário, a pergunta que se segue busca saber se o professor se sente motivado a participar das atividades de formação.

\section{Você valoriza os momentos de formação continuada na escola?}

- Sim não $\square$ As vezes 


\section{Gráfico 8- Valorização dos Momentos de Formação Continuada na escola.}

$100 \%$ dos professores expressaram que estão interessados na formação continuada no espaço escolar. Assim, mais uma vez, podemos identificar o interesse e o compromisso destes profissionais. Todos eles afirmam que veem nesse momento um período para se prepararem melhor para o desempenho da função que exercem. $O$ fato de valorizarem a formação remete-nos a uma demanda atual por professores que além de estarem preocupados com a formação, sejam também sujeitos autônomos nesse processo. Sujeitos pesquisadores.

Já na parte subjetiva do questionário, foi perguntado aos professores quais são os principais desafios que enfrentam no que se refere a sua formação continuada. Segundo eles, o principal desafio é o tempo. A profissão exige muito de cada um. É preciso ainda mais tempo para o planejamento das ações a serem desenvolvidas, para correção de atividades, cumprimento de atividades burocráticas e, muitas vezes as horas para a formação são diminuídas. Como podemos perceber na fala de uma das professoras:

"Mas como nossa profissão exige muito de nosso tempo ainda fica difícil dedicar parte de nossas horas para estudos mesmo, com o aumento das horas atividades. E o que vejo é que só com muita dedicação e abdicando de alguns momentos da vida pessoal é que conseguimos ampliar nossos conhecimentos" (Relato da professora A)

Através do depoimento desta professora, percebemos como a profissão docente exige do profissional que, muitas vezes, deixa de estar envolvido em suas atividades pessoais para o cumprimento de suas obrigações, bem como para o investimento em sua formação.

Outra professora também deixa claro em seu depoimento o empecilho da falta de tempo:

\footnotetext{
“As escolas estão oferecendo a possibilidade no próprio ambiente de ensino, já é um grande progresso, mas o tempo ainda é curto para a demanda de exigências escolares. Quando penso na formação continuada que cada professor tenta buscar individualmente, como especialização em uma das disciplinas que leciono na Escola, (Sociologia), o tempo, a falta dele, ainda é o maior entrave para a conciliação e busca de uma melhoria na prática docente.” (Relato da Professora B)
}

Aqui, percebemos que a professora destaca o avanço das escolas no que diz respeito a formação continuada, ressaltando que, isso foi possível graças a ampliação de horas extraclasse. Para ela, embora haja esse avanço, o tempo continua sendo o grande problema. 
Elaborar atividades, provas, corrigir em tempo hábil, realizar atividades burocráticas, como preenchimentos de diários, consumem muito tempo dos profissionais. Dessa forma, percebemos que o profissional deixa de investir em sua própria formação para que consiga dar conta de todas essas atribuições.

Embora ambos apresentem o maior desafio que enfrentam, os professores reconhecem a importância da formação continuada. Apesar do pouco tempo, mostram-se conscientes do inacabamento humanos e a necessidade de estarem em constante atualização.

Desse modo,

O educador, ser humano vital no contexto educativo, representa a possibilidade de transformação social. Através de seu autoconhecimento, em um caminho próprio de conhecimentos, torna-se possível também compreender o outro, ajudar o educando a compor uma realidade em seu entorno, percebendo e entendendo a necessidade de mudança no meio social em que está inserido. (ANTUNES; SANTOS, 2013, p. 297)

\section{Considerações Finais}

Com os enormes desafios que a educação enfrenta, a formação continuada de professores mostra-se com um dos caminhos que podemos trilhar na busca de soluções. Quando investimos nesse profissional estamos investindo em todo o processo educacional, pois como vimos, o professor representa uma possibilidade de transformação social. A qualificação, desse modo, refletese na educação como todo.

Ao analisarmos a ampliação do tempo extraclasse dos professores da escola José Martins Rodrigues em Quixadá-CE, podemos perceber que a nova carga horária aumentou as possibilidades de formação docente dentro do espaço escolar. De acordo com as informações prestadas pelos professores, observou-se que o tempo dedicado para a formação continuada saltou de uma vez por mês para uma vez por semana, organizados por área de conhecimento.

No que concerne ao profissional docente, ao tentarmos traçar um perfil desse profissional, percebemos que ele valoriza esses momentos de formação na escola e reconhece a necessidade de estar em contínua construção de seus saberes, de sua prática docente. Entretanto, o professor sinaliza que esse tempo ainda é insuficiente diante da quantidade de atividades dentro e fora de sala de aula.

Desse modo, podemos afirmar que o que muda na formação docente com a ampliação de carga horária é a possibilidade de fazer da escola um local ativo de qualificação profissional. A escola passa, então, a ser um espaço chave para que se desenvolvam ações que se voltem para a 
constante atualização e diálogo dos docentes. Os teóricos de educação e os próprios professores que contribuíram para esta pesquisa, convergem quanto a necessidade do constante processo de formação humana e, consequentemente, com a do profissional da educação.

Diante do dados analisados, é evidente que precisamos reconhecer os enormes avanços que a conquista do $1 / 3$ de planejamento representa para essa formação, entretanto, não podemos deixar de enfatizar que ainda é necessário avançar mais nesse assunto, uma vez que o professor ainda se sente angustiado com os desafios que a rotina de sala de aula apresenta, principalmente em relação ao tempo necessário para planejar suas aulas, elaborar e corrigir atividades e investir em sua formação. A formação continuada na escola, assim, auxilia a garantir uma qualidade maior da educação brasileira, para que tenhamos efetivamente uma educação transformadora de realidades sociais de todos os envolvidos no processo educacional.

\section{Referencias}

ANTUNES, Denize Dalpiaz; SANTOS, Betina Steren. Formação Docente: Processos motivacionais e subjetividade. In Educação e formação de professores: questões contemporâneas. BEZERRA, Ada Augusta Celestino, NASCIMENTO, Marilene Batista da Cruz. Fortaleza: Edições UFC, 2013.

BARRETO, Formação Docente e a relação entre a teoria e a prática: contribuições para o debate. IN Formação de professores e pesquisa em educação. ANDRADE, Francisco Ari de. SANTOS, Jean Mac Cole Tavares (org.). Fortaleza: Edições UFC, 2011.

BRASIL, Lei no 11.738 , de 16 de julho de 2008. Regulamenta a alínea "e" do inciso III do caput do art. 60 do Ato das DisposiçõesConstitucionais Transitórias, para instituir o piso salarial profissional nacional para os profissionais do magistério público da educação básica. Disponível em: <http://www. planalto.gov.br/ccivil_03/_ato2007-2010/2008/lei/111738.htm>. Acesso em: 03 abr. 2015.

FREIRE, Paulo. Pedagogia da Autonomia: saberes necessários à prática educativa. São Paulo: Paz e Terra, 2014.

FREIRE, Paulo. Pedagogia do oprimido. São Paulo: Paz e Terra, 1987.

NÓVOA, Antônio Concepções e práticas da formação contínua de professores: In: Formação contínua de professores: realidade e perspectivas. Portugal: Universidade de Aveiro, 1991. NÓVOA, Antônio. Professor se forma na escola. Portugal: Dom Quixote, 2000.

MARIN, Alda Junqueira. Educação Continuada: Introdução a uma análise de termos e Concepções. Cadernos Cedes. Campinas (SP): Papirus, n 36, 1995.

PIMENTA, Selma Garrido. Didática e formação de professores. São Paulo: Cortez, 2005. 
RODRIGUES, Margarita Victória; ALMEIDA, Maria de Lourdes Pinto, Políticas Educacionais e Formação de Professores em Tempos de Globalização. Brasília: Liber livros, 2008.

Recebido em: 01.12.2015

Aceito em: 31.10 .2016 